Fisheries, Volume 20, Issue 10 (October 1995), pp. 6 - 12.

http://afs.allenpress.com

http://afs.allenpress.com/archive/1548-8446/20/10/pdf/i1548-8446-20-10-6.pdf

Online ISSN: 1548-8446

Print ISSN: 0363-2415

DOI: 10.1577/1548-8446(1995)020<0006:PRFMAP>2.0.CO;2

(C) American Fisheries Society 


\title{
Problem-solving Research for Management: A Perspective
}

\author{
By Donna L. Parrish, Martha E. Mather, and Roy A. Stein
}

\begin{abstract}
We convened a symposium titled "Problem-solving Research for Management: Shared Responsibilities" at the 123rd annual meeting of the American Fisheries Society in Portland, Oregon. Our symposium sought to encourage researchers and managers to work together more effectively by reviewing successful research projects that have incorporated problemsolving approaches. In this first paper, we carefully define and distinguish between management and research by exploring the goals and tools of each discipline. In our view, problemsolving for management, as an iterative approach of which research is a major component, serves as a template for improving the relationship between managers and researchers as well as contributing to the solution of management problems. To improve the less-than-stellar record of interaction between these two groups, not only must problem-solving approaches be incorporated into the effort, but managers and researchers also must come to recognize, appreciate, and understand the differences in tools and goals of their respective trades. Unfortunately, we think neither group appreciates that successful management relies on rigorous, quantitative research that must be held accountable for providing management solutions. Managers and researchers clearly share the burden for the current state of fisheries science.
\end{abstract}

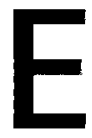

ven though an impressive array of resources and effort has been allocated to solving natural resource problems by management agencies, substantive management problems remain. Because we believe these problems cannot be solved without research, we convened a symposium titled "Problemsolving Research for Management: Shared Responsibilities" at the 123rd Annual Meeting (September 1993) of the American Fisheries Society (AFS) in Portland, Oregon. We believed that both managers and researchers share the burden for the state of our discipline, and as a consequence, we invited representatives from both groups to participate in our symposium. Our goal was to challenge managers and researchers to explore the means by which each could work more effectively with the other. To do so, we encouraged both groups to present examples of research that incorporated a problem-solving approach to solve an outstanding management problem. We present some of the insights gained during our organization of, and participation in, this symposium.
Specifically, we (1) define management and research and how their respective goals and tools influence interactions between managers and researchers; (2) provide a description of the problem-solving process; (3) discuss impediments to successful collaborations, especially discipline-specific differences in expectations, goals, constraints, methods, products, and time frames; and (4) provide cautionary advice that may serve to facilitate future management-research partnerships.

\section{Defining Management and Research}

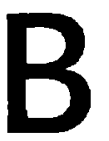
ecause this problem had to be bounded to fit within the constraints of a half-day symposium, we focused specifically on interactions between managers of U.S. state agencies and researchers at academic institutions. Though management is also conducted by federal agencies, and research is conducted within some state and federal agencies as well as private organizations, those interactions may not fit the following models we describe.

Donna L. Parrish is assistant unit leader for the Vermont Cooperative Fish and Wildlife Research Unit, School of Natural Resources, University of Vermont, Burlington, VT 05405; E-mail dparrish@clover.uvm.edu. Martha E. Mather is assistant unit leader of the Massachusetts Cooperative Fish and Wildife Research Unit, Holdsworth Natural Resources Center, University of Massachusetts, Amherst, MA 01003. Roy A. Stein is a professor of zoology, Aquatic Ecology Laboratory, Department of Zoology, 1413 Kinnear Road, The Ohio State University, Columbus, OH 43212. 
Management. Historically, management's goal has been responsible resource stewardship in accordance with public participation in consumptive and nonconsumptive uses. Broadly defined, the tools of management agencies include inventory, monitoring, enhancement through stocking, habitat restoration, control of exploitation, and research that solves extant problems. Given their source of funds, fisheries management typically views license holders as its client group, and consequently, many agencies place a high priority on managing sportfisheries. Jim Addis, administrator, Division of Resource Management, Wisconsin Department of Natural Resources (WDNR), in his symposium presentation, addressed the integration of fisheries research, management, and social issues into a partnership of researchers, managers, and anglers. This partnership was funded by the Federal Aid to Sport Fish Restoration Act (Dingell-Johnson and its amendment, Wallop-Breaux), which was established in response to demands for improved angling opportunities and scientifically based management. Although ecosystem management has become the mantra of federal agencies, Addis argued that state agencies primarily were concerned with the angler, the major contributor to their budget via Wallop-Breaux legislation and license fees. Owing to angler influence on management agencies, Addis concluded that most state agencies require strategies that respond first to angling concerns.

\section{Research. We first identify the type of science or} research that employs problem-solving techniques. Research can be defined as "a systematic and orderly process by which new knowledge is obtained in accordance with specified objectives" (Waters and Erman 1990). In Platt's (1964) definition, science is the "testing of multiple, falsifiable hypotheses." Though definitions of the scope and methods of science and research may differ, likely all will concede that in both research and science, questions must be clearly defined and then addressed with a focused, systematic research design. In our view, research or science can be characterized along a continuum ranging from basic to applied. Basic research seeks understanding in the long-term, resulting in a reservoir of knowledge. With applied research, we seek prediction in a shorter time frame, resulting in immediate application. The fisheries profession lies along this continuum, near the applied end, simply because fisheries is an applied field, and fisheries researchers are, by definition, applied researchers.

Interestingly enough, for fisheries research specifically, the value of prediction and understanding and their contributions to effective management has been addressed. Rigler (1982) discusses the value of prediction in his defense of empirical science; yet, later in the paper, Rigler states that the ultimate goal is explanatory science. More recently, Lehman (1986) and Peters (1986) debated the relative merits of these two goals. Their views can be analogized to holism and reductionism, where holism is equated to predictive power, and reductionism is equated to causality and derivation (Lehman 1986). However, most researchers doing predictive studies provide insight and understanding (Peters 1986). Not knowing why a relation exists prevents us from predicting under what conditions it will fail (Lehman 1986). Pragmatically, we agree with Lehman (1986); without understanding why relationships exist and what underlying mechanisms regulate it, we cannot manage any exceptions.

Understanding ecological mechanisms can help solve management problems, as revealed by Gary Isbell, executive administrator, Fish Management and Research, Division of Wildlife, Ohio Department
Solutions often are elusive without research directed at understanding the system. of Natural Resources (ODNR). At the AFS meeting, Isbell and The Ohio State University's David A. Culver jointly received an award for the "best" research project funded by Federal Aid to Sport Fish Restoration funds for developing techniques that dramatically improved walleye (Stizostedion vitreum vitreum) and saugeye ( $S$. vitreum $\times S$. canadense) produced via extensive pond culture. Surprisingly, Culver et al.'s (1992) work dealt with Daphnia production. One might ask, How many management agencies would fund this research, and how often would such seemingly esoteric research provide answers to management questions? However, from Culver's study, we now understand the temporal production of Daphnia, an important food for larval and juvenile fish. In addition, in Ohio hatchery ponds, we now know how this productivity responds to delayed pond-filling and how the application of inorganic fertilizers drives Daphnia production. Consequently, techniques are now available to Ohio DNR that overcome historical problems with extensive culture of walleye and saugeye. Immediate applicability came with this study because percid production has increased six-fold in Ohio hatchery ponds, where Culver's techniques have been applied. Annual continuing-education workshops, led by Culver, keep hatchery managers current about rigorous limnological methods to assess pond productivity. Clearly, this research, which might be considered expensive by many agencies, has solved an outstanding management problem that will provide a long-term, cumulative, positive impact on Ohio's percid fisheries.

\section{Interactions between Management and Research. \\ Cushing (1974) sought to link science and man- agement, concluding} that good science meant good management. In our symposium, Isbell and Addis revealed their respective 
thoughts regarding Cushing's perspectives. Isbell argued that research often fails to meet management needs.

However, he simultaneously portrayed fisheries research associated with his agency, through a partnership with The Ohio State University, as integral to Ohio's approach to managing fishery resources. From Addis's viewpoint, problem-solving research was necessary to implement science-based management.

In our view, research is multifaceted; some features involve and relate to management, whereas others do not. Likely, all aspects of fish research, applied and basic,

\begin{tabular}{c}
\hline The absence of \\
common expecta- \\
tions compromises \\
successful \\
collaboration. \\
\hline
\end{tabular}
have value in some arena. Understanding how things work benefits many users and perhaps should be done someday by somebody with some agency money. However, fisheries management agencies should not pay for research that does not benefit their management programs directly. If ecological, behavioral, physiological, genetic, and social mechanisms could be bypassed, the most cost-effective use of management funds certainly would be to short-circuit understanding and simply predict the answer. In reality, however, we live in a complex and variable world. Solutions often are elusive without research directed at understanding the system.

The question of what specific research directly benefits management is further complicated because applicable results are typically drawn from a reservoir of basic science, often through serendipity. Because we are not prescient, we cannot predict what information, gathered under the guise of basic research, will be valuable for solving future management problems. Thus, the needs of managers, applied researchers, and basic scientists are best served by continuing to build, at some level, this pool of potentially useful information.

Whereas researchers seek to conduct quantitative, rigorously designed experiments and field manipulations, managers pursue goals that are more diverse and complex. Managing resources is exceedingly complicated because science is only one source of information for generating management decisions (Pringle 1985). Researchers must appreciate and respect these multifaceted goals and nonscientific constraints on managers. We believe that the challenge for both researchers and managers is to recognize and respect the differences between their disciplines and to work together to identify those overlapping areas of interest where each can gain from the other.

\section{Problem-solving: Definition and Description}

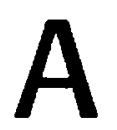

$s$ an integrative, synthetic process, problemsolving seeks a solution to a problem. Applied research provides critical information to this process; however, to be effective with applied research, we first must understand underlying explanatory mechanisms that may only be obtained from basic science. Problem-solving resource management, as defined by
Barrett (1985), includes research in the majority of his 19step algorithm. Interestingly, the first step in this interactive process is the most difficult, i.e., problem identification (Barrett 1985). Issues, identified as problems, are established based on goals, objectives, and values of management (Barber and Taylor 1990). After problem identification, available data from management agencies or previous research should be used to generate an effective research design. Though most fisheries biologists are trained in conducting experiments; managers traditionally are not trained in experimental approaches (McAllister and Peterman 1992). Rigorous experimental designs are required to distinguish among alternative explanations of real-world observations (Barrett 1985; Waters and Erman 1990; McAllister and Peterman 1992). Frequently, management relies on trial and error or passive adaptive approaches. However, using an active adaptive strategy that incorporates "learning by doing" would provide the understanding required for appropriate adjustments to management plans through time (DeVries and Stein 1990; Walters and Holling 1990). Just one example of where active adaptive management was not implemented, and transient processes were ignored, is the Canadian Salmonid Enhancement Program (SEP) (Walters and Holling 1990).

Research results also should provide direct feedback to Researchers must appreciate and respect these multifaceted goals and nonscientific constraints on managers. management

for increasing the effectiveness of monitoring programs. High-quality monitoring can actually reduce the number of steps required for solving future problems. These monitoring schemes should be jointly developed by managers and researchers. Whereas data collection by management agencies, via surveys and monitoring programs, is critical to identifying problems, to be of value these programs must be statistically rigorous, spatially appropriate, and standardized to gear type. One must, in turn, recognize that collecting data, even long-term, does not qualify as research. To understand complex interactions within ecosystems, a hypothesis-testing approach likely will be required.

\section{Expectations, Communication, and Appreciation}
A
$\mathrm{s}$ in any relationship, problems with the man- ager-researcher relationship cannot be attrib- uted solely to one participant. Rather, these relationships founder owing to many problems: absence of common expectations; poor communication; poor appreciation for one another's discipline, especially related to funding, research products, use of graduate students, and researcher independence; incompatible goals; and educational differences. In the following text, we provide what we consider constructive thoughts specific to each of these problems. 
The absence of common expectations compromises successful collaboration. In our view, the major obstacle to solidifying positive manager-researcher relations regarding problem-solving derives from the simple fact that research typically does not solve management's problems (Cullen 1990). We believe researcher credibility lies at the heart of the failure of manager-researcher collaboration. Researchers have not solved management's problems because they continue to use time-worn techniques when, in fact, these problems require new, creative approaches. The research community must maintain a high-quality program that incorporates recent literature and technological advances (e.g., using sophisticated hydroacoustics gear and physiological telemetry to improve bioenergetics models for managers' use (Ney 1993). To stimulate and enhance creativity, researchers must communicate among themselves and with managers. Participation in scientific meetings, workshops, and seminars; continual literature review; and interactions with international colleagues all serve to improve communication. Continuing education and seminar programs that feature researchers and managers are invaluable for communicating new skills and providing a forum for discussing issues. Professional interactions flourish in an environment of frequent contact regarding issues associated with the field.

Poor success, as perceived by managers, also can be related to the failure of both sides to acknowledge the scope and difficulty of most management problems. To manage a fishery successfully requires much information. To provide angler satisfaction may require information from at least eight problem areas: how physical and chemical factors influence water quality and system productivity; how changing land-use patterns influence these abiotic components; how recruitment is determined; how trophic interactions-especially food availability, competition, and predation-influence sport-fish survival and growth; how regulations influence fish population structure; how the angler perceives and complies with regulations; how these issues change through time and across systems; and how a monitoring program might be designed to acquire the information necessary for management. To expect a few studies, no matter how well-planned and executed, to provide all of this information is simply unrealistic. Poor understanding of any one of these areas may engender a feeling that research has failed if a proposed management strategy comes up short. Managers, in conjunction with researchers, should create long-term, big-picture strategies that conceptualize problems that can be solved in a realistic time frame and

can contribute to the solution of a larger problem. Although all parties

require short-term products from such a strategic plan to survive professionally, i.e., reports, papers, and management recommendations, the failure to realistically identify the scope of fish management problems seems to doom all research to some level of failure and disappointment. Comparing the immensity of the problem to the almost insignificance of each realistically identified, but accomplishable, piece of research can be depressing at the outset. However, review after 5 or 10 years will provide researchers and managers, who have developed and followed such a strategic plan, the satisfaction of substantive progress.

Another stumbling block to building trust between researchers and managers is a failure by both sides to acknowledge uncertainty as an omnipresent force. When 
research or monitoring is inadequately supported, error or uncertainty will most definitely result because of insufficient effort. Even when adequately supported, natural variability often compromises the precision of results. As a natural consequence, faith in the ability of research to solve problems declines. Though the steps needed to deal with this variability are unclear, we provide the following advice. First, researchers should clearly qualify their conclusions, based on the uncertainty inherent in their predictions or generalizations. Second, managers must appreciate that interpreting uncertainty

\section{To foster a greater appreciation and understanding of the research and management disciplines, students should be encouraged to pursue internships with both management agencies and research entities.}

will be part of any set of recommendations, no matter how thorough and applicable the study. Finally, researchers must develop tools to help managers explain their uncertainty to the public. Following these guidelines should advance the professional interaction between managers and researchers.

Often, researchers and managers fail to appreciate the constraints of one another's discipline. To survive professionally, researchers need to acquire funding, publish papers, and train students. In the manager-researcher interaction, the matter of establishing the level of project funding is many times the most contentious issue and typically is based on differing expectations. The research component of a problem-solving exercise cannot be accomplished without adequate funding, even given nearly universal budgetary constraints. Management agencies wrestle with problems that have been extant for years. As a consequence, they should not expect these problems to be solved by funding a project with a graduate-student stipend, a few dollars for supplies, and a few years worth of time by a master's or doctoral student. Inevitably, small investments beget few (and often unreliable) answers. Underfunded projects perpetuate the stereotype of researchers being unable to solve management problems. Hence, managers and researchers both need to acknowledge the real cost of solving a longstanding management problem. If the project cannot be adequately funded, then managers and researchers should agree to address a smaller question (within the context of the larger issue) or wait until sufficient support becomes available. Unfortunately, researchers often will agree to accept an inadequately funded project under the principle that some money is better than no money. Researchers clearly have a responsibility (if not to themselves, then to naive students who become sacrificial offerings to the graduate-education gods) to avoid projects that are underfunded to the extent that failure is the only outcome that can be predicted with any certainty.

Products of research projects can themselves be sources of misunderstanding. Often, benefits of a report to the funding agency seemingly conflict with the peerreviewed publications researchers seek. In our view, both forms of communication are critical to the success of problem-solving projects. Management agencies require reports, which are submitted immediately post-project. Researchers require publications, for these papers are the currency of their discipline. We believe agencies also benefit from peer-reviewed publications. Without these publications, and the rigorous review they undergo, agencies will not know if the results are accepted by other researchers and managers. As one example, the AFS Publications Overview Committee strongly encourages authors to avoid citing technical reports (see "Guide for Authors," North American Journal of Fisheries Management) because the reported results have not been peerreviewed. Peer-reviewed publications provide positive reinforcement to managers who fund projects of sufficient rigor to pass external scrutiny.

Using graduate students on projects often is questioned by managers, but a major responsibility of university researchers includes student training. Whereas a graduate stipend is much less than the salary of a technician, a graduate student has obligations beyond the project, including attending classes, reading literature beyond the project, serving on university committees, and attending seminars and scientific meetings. As a result, graduate students bring diverse and creative ideas to the research effort. Also, the thesis or dissertation may extend beyond the scope of the funding effort, including information perhaps ancillary to managers' needs yet critical to a basic understanding of system function. Projects done with graduate students should involve a collaborative effort among the advisor, student, and management agency. From the managers' perspective, one of the negative aspects of graduate-student research derives directly from principal investigators who fail to assume ultimate responsibility for the project. In almost all cases, graduate students cannot be held legally accountable for the completion of a funded project. Therefore, researchers need to understand their obligation and be directly involved in project activities.

Managers have constraints on their time that researchers often fail to appreciate. Managers need answers now. Agency biologists need to be able to implement effective regulations quickly and justify their effectiveness to the angler, legislator, and public in annual budget negotiations. Conclusions from research that begin "in general," "sometimes," or "on the one hand" coupled with the absence of specific management recommendations are of little value to agencies.

Researchers prefer to maintain a high degree of independence, which can be interpreted as a lack of accountability. Because management agencies are held strictly accountable for expenditures of money and time, researchers must be sensitive to their timeliness, budgets, 
etc. Once a common problem has been identified, researchers must be responsible about conducting projects within specified time frames, submitting reports on time, and operating within project budgets. Increased communication and continual feedback about problems, successes, and constraints related to research and management can aid in addressing and preventing these problems.

Clearly, managers and researchers view the fisheries world differently. To this point, although we have reviewed their different goals and tools, we have not reflected on their educational backgrounds. Researchers and managers often have been educated side-by-side in departments of fisheries and wildlife or biological sciences at the undergraduate and graduate levels. Some academic researchers obtained undergraduate degrees in fisheries, whereas some management biologists matriculated in the biological sciences. Typically, academic researchers hold a doctoral degree with more experience in research. Conversely, the majority of management biologists hold master's degrees with less experience in research. Differences in terminal degrees for managers and researchers may be reduced in the future because state agencies are now hiring staff biologists with doctorates to direct research programs and develop scientifically based management.

Adelman et al. (1994) surveyed Minnesota and Texas state fisheries and wildlife biologists to determine what university courses were completed and which courses were most important to job performance. The results are interesting and somewhat alarming. These professionals thought design and evaluation of research programs and experimental design and statistical sampling should have been emphasized more, whereas calculus, ecology, genetics, and evolution should be de-emphasized. Without a background in ecological and evolutionary theory and some math skills (even basic population models require differentiation), designing and evaluating research programs will be nearly impossible. Respondents also thought that strategic and long-range planning, budget preparation, employee supervision, and conflict resolution should be emphasized. These courses address areas that are necessary when individuals advance to higher levels of management. We believe (perhaps naively) that these skills could be accumulated through in-service training when the demands of the position require that knowledge. These skills often are learned at some level through life's experiences and the maturation process.

We must be ever-vigilant that university degrees emphasize the biological sciences (Hard 1995). Whereas we recognize the need for an appreciation of the social, economic, and political aspects of fish management, we do not believe this appreciation should be achieved in lieu of biological training. A good grounding in the basic sciences is required to adequately evaluate research. To foster a greater appreciation and understanding of the reearch and management disciplines, students should be encouraged to pursue internships with both management agencies and research entities. Ideally, these internships 
would be organized to provide intellectual stimulation as well as participation in practical activities.

In the question-and-answer period of our 1993 symposium, Jim Addis was asked what was academically needed to become a good management biologist. He argued for applicants with a solid biological background and some knowledge of the social, economic, and political arenas. However, because of the complexity of social and economic issues, Addis would seek to hire a resource economist or social scientist with a natural resources background, rather than to expect biologists to do this job. We couldn't agree more! Unfortunately, in many

\section{Good research serves as the scientific justification for good management.}

cases biolo-

gists no longer have time to "do biology" and instead are embroiled in

the human dimensions aspects of the fisheries profession. Fisheries management is not well-served by expecting biologists to be "jacks of all trades." Surely, it is objectionable, if not laughable, to social scientists and economists that agencies choose to assign biologists with two courses in the social sciences to roles for which social scientists and economists have invested many years of their lives obtaining advanced degrees. Given its complexity, effective fisheries management must be a multidisciplinary pursuit.

\section{Potential Approaches to Management Problems}

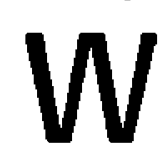

e (Mather et al. 1995, this issue) conducted a survey to determine what current problems occupy a manager's time. Our symposium speaker topics were cross-referenced with the top management issues identified in the survey. In their talks, symposium participants described the nature of the problems they were addressing, talked about past approaches and why these had failed, and suggested new creative approaches. Several recurring themes were identified in these presentations concerning past approaches, including a lack of evaluation, insufficient science, and no realistic goals (e.g., Johnson and Martinez 1995, this issue). Traditional approaches sought to solve the problem immediately rather than to develop a science-based strategic plan-precisely those shortcomings we have discussed. Using this example and our cautionary tale of research-management interaction, we believe the relationship between research and management can be improved and can benefit our fisheries resources.

We close by emphasizing that research is not a luxury. Good research serves as the scientific justification for good management. However, much research claims to address the needs of managers when it doesn't. Common ground must be sought where researchers and managers can work together to their mutual benefit-and to the benefit of aquatic ecosystems.

\section{Acknowledgments}

We are grateful for the high-quality presentations by the following authors at the 1993 symposium: Jim Addis, Mark Bain, Mark Bevelhimer, Dennis DeVries, Jeff Hard, Gary Isbell, Brett Johnson, Patrick Martinez, and Russell Wright. We appreciate the reviews of Jim Addis, Gary Isbell, and Ken Williams. The Vermont Cooperative Fish and Wildlife Research Unit is supported by the National Biological Service, Vermont Department of Fish and Wildlife, University of Vermont, and Wildlife Management Institute. The Massachusetts Cooperative Fish and Wildlife Research Unit is supported by the National Biological Service, Massachusetts Division of Marine Fisheries, Massachusetts Division of Fisheries and Wildlife, University of Massachusetts, and Wildlife Management Institute.

\section{References}

Adelman, I. R., D. J. Schmidly, and Y. Cohen. 1994. Educational needs of fisheries and wildlife professionals: results of a survey. Fisheries 19(11):17-25.

Barber, W. E., and J. N. Taylor. 1990. The importance of goals, objectives, and values in the fisheries management process and organization: a review. N. Am. J. Fish. Manage, 10:365-373.

Barrett, G. W. 1985. A problem-solving approach to resource management. BioScience 35:423-427.

Cullen, P. 1990. The turbulent boundary between water science and water management. Fresh. Bio. 24:201-209.

Culver, D. A., J. Qin, S. P. Madon, and H. A. Helal. 1992. Daphnia production techniques for rearing fingerling walleye and saugeye. Final Report. Federal Aid in Sport Fish Restoration Project F-57-R, Ohio Department of Natural Resources, Division of Wildlife, Columbus.

Cushing, D. H. 1974. A link between science and management in fisheries. Fish Bull. U.S. 72:859-864.

DeVries, D. R., and R. A. Stein. 1990. Manipulating shad to enhance sport fisheries in North America: an assessment. $\mathrm{N}$. Am. J. Fish. Manage. 10:209-223.

Hard, J. J. 1995. Science, education, and the fisheries scientist Fisheries 20(3):10-16.

Johnson, B. M., and P. J. Martinez. 1995, this issue. Selecting harvest regulations for recreational fisheries: opportunities for research/management cooperation. Fisheries 20(10):22-30.

Lehman, J. T. 1986. The goal of understanding in limnology. Limn. Ocean. 31:1160-1166.

Mather, M. E., D. L. Parrish, R. A. Stein, and R. M. Muth. 1995, this issue. Management concerns of state fisheries agencies: results of a time allocation survey. Fisheries (10):14-21.

McAllister, M. K., and R. M. Peterman. 1992. Experimental design in the management of fisheries: a review. N. Am. J. Fish. Manage. 12:1-18.

Ney, J. J. 1993. Bioenergetics modeling today: growing pains on the cutting edge. Trans. Am. Fish. Soc. 122:736-748.

Peters, R. H. 1986. The role of prediction in limnology. Limn. Ocean. 31:1143-1159.

Platt, J. R. 1964. Strong inference. Science 146:347-353.

Pringle, J. D. 1985. The human factor in fishery resource management. Can. J. Fish. Aquat. Sci. 42:389-392.

Rigler, F. H. 1982. The relation between fisheries management and limnology. Trans. Am. Fish. Soc. 111:121-132.

Walters, C. J., and C. S. Holling. 1990. Large-scale management experiments and learning by doing. Ecology 7:2060-2068.

Waters, W. E., and D. C. Erman. 1990. Research methods: concept and design. Pages 1-34 in C. B. Schreck and P. B. Moyle, eds. Methods for fish biology. American Fisheries Society, Bethesda, MD 